\title{
Strategic Partnership Between Private Organizations and Universities: The Search for Regional Development Through Solutions for Hospital Management
}

\author{
Jamerson Viegas Queiroz, Abner Vicente Braga, Fernanda Cristina Barbosa Pereira Queiroz, \\ Jéssica Monyk Tiburcio de Souza, Renata de Oliveira Mota \\ Universidade Federal do Rio Grande do Norte, Natal, Brazil
}

\begin{abstract}
The public power and the private enterprise, the main agents of national economic and social development, when cooperating strategically, promote increased functional efficiency of their activities. In order to highlight the relevance of such partnership, this article aims to analyze the potential of actions jointly developed by private organizations and Brazilian universities. The research problem is lined in the field of health, which hosted actions developed between the Federal University of Rio Grande do Norte (UFRN) and the Hospital Maternity Guiomar Fernandes (HMGF), located in the city of Alexandria, in Rio Grande do Norte. The study emphasizes the shortcomings of this organization, the resolving power of the university in this scenario, and performs the analysis of the effects of this cooperation. The methodology used in this research was the case study in HMGF. With emphasis on fundraising and improving the informational management system, funding sources for projects of restructuring and expansion of the hospital were sought, as well as initiatives for developing hospital management softwares for small- and medium-sized organizations. As a result, the articulation between the university and the hospital provided the elaboration of a project for software development and the production of a project for physical restructuring and technological investment, aiming to expand the supply and quality of the hospital's services. The implementation of information systems, associated with investments in hospital infrastructure, providing increased efficiency in public assistance to the population, bringing both local and regional benefits, besides, providing the authorities with relevant data on the development of public policies.
\end{abstract}

Keywords: fundraising, hospital management, information system, strategic cooperation

Jamerson Viegas Queiroz, Doctorate in Production Engineering, Department of Production Engineering, Universidade Federal do Rio Grande do Norte.

Abner Vicente Braga, Graduate Student in Production Engineering, Department of Production Engineering, Universidade Federal do Rio Grande do Norte.

Fernanda Cristina Barbosa Pereira Queiroz, Doctorate in Production Engineering, Department of Production Engineering, Universidade Federal do Rio Grande do Norte.

Jéssica Monyk Tiburcio de Souza, Graduate Student in Production Engineering, Department of Production Engineering, Universidade Federal do Rio Grande do Norte.

Renata de Oliveira Mota, Graduate Student in Production Engineering, Department of Production Engineering, Universidade Federal do Rio Grande do Norte.

Correspondence concerning this article should be addressed to Jamerson Viegas Queiroz, Department of Production Engineering, Universidade Federal do Rio Grande do Norte, Natal, Brazil. E-mail: viegasqueiroz@gmail.com. 


\section{Introduction}

The accelerated development of information globalization imposes, the dawn of new and complex technologies, the different ways of seeing the business environment, the relentless pursuit by the competitiveness of market are all factors which fall into an important tool vividly in the current techno revolution: knowledge. In this way, the correct operation of knowledge brings with it the opportunity to incorporate important information to business decisions, allowing them the possibility of achieving greater and better results on the market.

It is exactly within this context where the partnership between university and company is inserted. The university, generation and dissemination of knowledge, becomes a powerful ally and licensor of process necessary to reach this knowledge. Companies look at a media holding which does not have access, or not know how to make use of decisive way. On the other hand, the university has the opportunity, as an institution of teaching, research, and extension, it can be inserted into the socio-economic reality of the country, to the same extent that provides the students an early integration with the labour market, managing to form people engaged in the problems the country faces, and better prepare them for the timing of egress.

The problem of public health, while the industry filled with urgent needs and administrative mistakes, falls in search of evidence of the power of the resolutive problems experienced by private companies operating in this sector. There is evidence that in addition to these, it is necessary to promote joint actions with the participation of health workers, the private sector, and civil society.

The Ministry of Health in Brazil was established with the law $n^{\circ}$ 1,920 (Brasil, 1953) and is the executive branch entity that has the responsibility to organize and draw up plans and public policies in search of promotion, prevention, and health care of the citizens of the country. Despite the campaigns and projects developed by the ministry and from existing improvements when carried out a comparison with data from previous years, the Brazilian public health still reveals troubling features, requiring immediate actions to change that reality.

In this context, the unified health system (SUS) in Brazil is the universal service system, namely, aims to cater to all Brazilians, without any kind of distinction of resources among patients without cost to them, where they receive care can be equivalent to your needs. In practice, the conditions of the SUS are quite different: according to the website of the Ministry of Health on the internet, the IDSUS (system performance index of health), created by the federal government, points out that Brazil has IDSUS 2012 equivalent to 5.47—in an average from zero to 10 -showing that much of the population lives in cities with lower indices of quality of services than the ideal.

It is based on the above so that the present article aims to analyze the potential of general actions developed by Brazilian universities and private organizations in seeking to promote an alternative solution to the shortcomings highlighted today in the public health sector.

Based on these questions, the search issue revolves around the following question: How and to what extent the university is able to serve as a partner to assist in solving the problems of strategic and financial nature of a hospital of Rio Grande do Norte? To answer this question, it was for funding sources that can fit to the reality of the institution, serving as support for the achievement of projects that would ensure the immediate needs for this organ.

With increasing significance, the article is divided into chapters and sub-chapters that start with the 
introductory perspective, followed by theoretical tooling where the themes of the third sector and fundraising for this are presented. It is therefore pointed to the option search methodology, which highlights the ways in which the research was conducted. Soon after, the structuring of the remarks related to the case study — where are the search results, so that, subsequently to be presented the concluding remarks in conclusion, in addition to suggestions for further work. The job is terminated with the bibliographic reference used in the search.

\section{Fundraising in the Third Sector}

As for Olak and Nascimento (2009), the third sector is made up of private institutions with the specific purposes of lead changes and whose patrimony is constituted, maintained, and expanded from contributions, gifts, and grants and that, in any way, it reverts to its members or maintainers.

The main causes of the growth of the third sector (Olak, Slomski, \& Alves, 2008) are summarized as follows:

(1) Crisis in the public sector and consequent reduction of resources allocated to social areas; (2) volunteer growth, driven by increased awareness of the people, media support and standardization of this service; (3) growth of urban and rural violence; and (4) greater business involvement, trying to captivate consumers with corporate citizenship policy. (p. 32)

According to Silva, Menezes, Barbosa, and Felizola (2011), philanthropy, which is at the origin of the third sector, is a very ancient phenomenon and is characterized as a continuing action to donate money or other goods in favor of the institutions or persons. This practice is generally adopted by wealthy individuals, known as philanthropists or philanthropic people.

In this sense the term "third sector" has been used as opposed to the concept of first and second sector and that basically the third sector is not part of the public sector and has no interest in profit (Niyama \& Silva, 2008).

Seen it, Villas Bôas Neto, Stefani, and Pezzi Junior (2003) stated that management in the third sector is something that differs from the management of other private companies, because:

The management of the third sector, in spite of using traditional management tools, it does through adaptations that there are administrative groups on a daily basis and they begin to be treated in courses and materials for this area-specific management. (p. 60)

Inserted in this context, the fundraising activity won, in recent years, great importance and came to be seen as an action that should be undertaken with increased dose of professionalism, given their significance for the survival of the institutions, since they may not be expecting that only the government provides the necessary resources so that they can keep, or be at the mercy of donations, what press the institutions to search other investors sources, making the fundraising activity more efficient and dynamic.

The philanthropic, non-governmental and non-profitable organizations do not achieve their goals due to problems faced in fundraising, which precludes the development of projects (Sartori, Franco, \& Pereira, 2003). In this way, the success in fundraising depends on the relationship that is established by the donors, who are persons or institutions which usually share the mission, values, and objectives of the organization (Szazi, 2005; Pereira, 2006; Tachizawa, 2007).

The stiff competition for resources available, the need to measure and assess the performance of managers, internally as well as to determine the feasibility of projects, fundraising, all these factors compel organizations to improve and innovate ways to capture (Adulis, 2001, 2002a, 2002b). According to Falconer (1999) and 
Tachizawa (2007), the main sources of financial resources are the cooperative agencies, foreign institutions, the sale of products/services, government bodies, companies, foundations, and individual donors.

It is essential that the funded projects add value to the organization, helping to build its history and contributing to the creation of organizational skills that help in getting new features (Cruz, 2012). Developing fundraising strategies facilitate the adaptation of organizations to changes and requirements of funding sources, to ensure the sustainability of their goals and initiatives. With the expansion and diversification of sources of funding, organizations reduce the vulnerability and subordination typical of when it depends on very few sources of funds (Valarelli, 1999).

\section{Methodology}

For the completion of the current work, the methodological option chosen was the case study of the exploratory and descriptive type based on reality and the characteristics of the object of study.

As research, the case study can be essentially exploratory, being used as a basis for obtaining preliminary information about the object of interest. May also be analytical, where one seeks to discuss the object under study, build or develop a new theory in order to confront it with something that already exists. To be essentially descriptive, it aims to describe some of the case study. An exploratory character work is viable as a pilot study of a large-scale research, whereas the descriptive study is necessary for the preparation of an intervention.

For Goode and Hatt (Lazzarini, 1995), the technique is "one way to organize the data in terms of a given unit chosen". Yin (2005) stated that the case study is an empirical research, a method that covers everything — planning, data collection, and technical analysis of the same.

Yet about the theme, Yin (2001) stated that the case study is a scientific research that investigates a contemporary phenomenon within its real-life context, especially when the boundaries between phenomenon and context are not clearly defined; facing a situation technically only in that there are more variables of interest than data points and, as a result, is based on multiple sources of evidence (...) and benefits from the prior development of theoretical propositions to drive the collection of data analysis.

Accordingly, this study deals with the elaboration of financing plans for obtaining the financial resources for a non-profit organization, deployed from the analysis of their reality.

To this end, the fieldwork lasted from March 2012 to December 2012, during which time he explored the characteristics of Maternity Hospital Guiomar Fernandes (HMGF) from the point of view of knowledge gained at the academy, general purpose of an extension project approved by the Federal University of Rio Grande do Norte (UFRN). The research had the same coordination of research project, a professor of industrial engineering at the university.

Thus, in a first step the objective of the bibliographical research with regard to funding sources available to establish what and with what focus these could be employed for the purposes which are necessary for the institution, as well as allow its authors foundation enough to direct them in the implementation of the current work. To achieve that goal, the researchers worked with authors that deal with specific themes, in conjunction with consultations of scientific articles and research in databases like portal of periodic.

Capes, in a later step, aimed at the diagnosis of the situation of the HGMF regarding financial funding to the everyday reality of the hospital, as well as its physical structure, professional framework, shortcomings, and needs. For this purpose, were made trips to the institution's city, in order to do an active observation. As the central data collection techniques utilized to documentary research in financial reports prepared in the file, as 
well as access to documents on the legal status of the hospital, statistics on the number of calls made, medical equipment; and meetings with the directors, managers, and other employees of the hospital.

In the third step, the data coming from the previous step were analyzed in a qualitative way, in search of interpretation of these for the moment of the proposition of financing plans. From previous point was developed some fundraising projects that meet the interests of the organization, preparing and submitting three projects financing as financing institutions concerned model.

\section{Case Study}

\section{History and Description of the Main Initiatives}

The HMGF is a health establishment of charitable purposes, with certificate of Social Assistance Beneficent Entity (CEBAS), founded on May 1, 1956, initially to meet the demand of population of Alexandria, city of Rio Grande do Norte, today with 14,000 inhabitants. Featured in founded as maternity hospital, HMGF today offers a range of services that the ranks as a general hospital.

In the last 10 years the hospital developed quickly, passing through a reform of the physical structure and deployment of new equipment and services, funded by the Ministry of Health, through the project ReforSUS, which provided duplication of its installed capacity—developing administratively and technically, with bigger and better resolving power, plus a considerable improvement of the quality of care. Currently, its area of influence is distributed in the municipalities of the sixth Regional Health of Rio Grande do Norte, Northeastern semi-arid region, comprising 36 municipalities and some other of the 2nd Regional Health/RN, covering an area with a population of more than 400,000 people, as well as neighboring municipalities in Paraíba, all serviced exclusively through SUS.

Offers services identified by three fundamental classes: outpatient clinic (related to clinical consultations), clinical and surgical inpatient (referring to the patient's hosting), as well as diagnostic support through imaging tests and laboratories. Outpatient services offered are divided into the following categories: medical clinic, gynecologic, orthopedic, obstetric, angiologic, pediatrics, cardiology, gastroenterology, ophthalmology, in addition, speech therapy and physical therapy services.

Among the surgical services are offered: general surgery, vascular, ophthalmic, orthopedic, obstetric, gynecologic, and otorhinolaryngologic dermatological. There are also image diagnosis support via ultrasound, endoscopy and radiology, electrocardiography, as well as clinical analysis laboratory services and microbiology, still with the inpatient services, urgent and emergency. Also in the field of diagnostic electrocardiography, support that integrates the cardiac telemedicine service, in which the exam is done at the health facility and is analyzed and the report issued by a professional in another location, this made possible thanks to the transmission of information across the World Wide Web, which provides flexibility to the institution in the diagnosis of their patients since there is no medical need to be physically present for review of that examination.

There is also the Hospital Epidemiology Service (IF) that brings together all the information of the hospital health and compulsory notification services, as well as the national network of integral attention to health of a worker who is a network of sentinel "medical services and ambulatory of medium and high complexity responsible for diagnosing the accidents and work-related diseases and by registering them in the information system of reportable diseases (SINAN-NET)” (Ministério da Saúde, 2012).

The HMGF offers a Center of Material and Sterilization (CME) that employs advanced technology to 
monitor the results achieved through modern validation evidence, besides industrial laundry, electric generator, and Waste Management Program in the Health Service-PGRSS.

Are eighty-seven (87) professionals involved in the dynamic daily, of which twenty (20) are doctors, thirty (30) nursing professionals, ten (10) technical areas of support professionals, and twenty-seven (27) general service staff.

The wealth of the hospital is composed of assets acquired through purchase or donation. Currently there is an installed capacity of fifty (50) beds in the national register of Health Establishments (CNES); Surgical Center with three (3) operating rooms, as well as structure and equipment for physical therapy services, speech therapy, and occupational therapy.

The maintenance of this structure has a high cost, which is aggravated by the meager income of the hospital. By attending exclusively via SUS, regular income is restricted to the payment of the procedures performed, which is a fixed amount, established by the MS and applied to all health units.

Other features are the parliamentary amendments, approved resources in the annual budget of the union, or of the state. These revenues, in turn, are for specific purposes, such as purchase of equipment, medicines, and equipment, making it possible to target them to payments of fixed costs, such as salaries and maintenance. Another feature of this type of resource is the fickleness, not possible to stipulate certain deadlines for their receipt.

The low volume of resources makes investments in various areas, especially in those that demand the most expressive values. An example of this is the creation of a diagnostic imaging center, which would correspond to the region of the high West Brazil today without a structure, requiring often going to the capital to carry out examinations. In addition, a technical limit to the expansion of cardiac telemedicine service is the poor quality of internet service in the city, restricting the capacity and range of exams that could benefit.

Another challenge faced by HMGF is also true in other institutions of similar profile, which is low managerial and operational efficiency, sometimes explained by low supply of instruments that aim to meet the demands of a health unit for small and medium businesses, being almost non-existent software accessible for this slice of the market. The development of software of this kind demands high investments and time to maturity and implementation.

\section{Partner HMGF/UFRN}

Acting together at the Federal University of Rio Grande do Norte with HMGF was one of the actions planned for the development of strategies on fundraising for the hospital. Through the technical expertise provided by UFRN, extension actions were developed aiming at the improvement of the health unit. The partnership provided to both development, since when approaching a social institution the university gives to its members better reading of the external reality, seeking applications of universities' theories and improving its techniques, establishing a link between students and the society that allows them greater understanding of what is learned in the academy. While the hospital receives the contribution of students, teachers, and technicians, often in contact with innovative solutions and channelized for various surveys.

There is a deficiency in the institutions in general, especially in smaller, pros to develop projects aiming to plead financial entities with the resources or even companies. This grace period deepened when we leave public sector organizations or non-profit. Thus the partnership HMGF/UFRN was established in order to build projects to enable the hospital to request funding, sponsorships, and donations to carry out its goals. In addition 
to projects of this nature, there also developed other seeking to improve the quality of information, developing ongoing evaluation mechanisms, both as an information management system.

\section{Results}

Accurate analysis of existing demands in the hospital revealed structural, managerial problems, and staff. From these projects were elaborated demands aimed at raising funds for investment in strategic areas.

A situation observed in HMGF was the absence of an integrated system of hospital management, which would give employees greater accuracy on the information, providing increased operational efficiency, both for greater agility and the ability to better control, reducing waste, and freeing up resources. In order to meet this need, there developed a technology information system focused to manage small- and medium-sized hospital institutions. Through a business plan encompassing market and competitiveness analysis, analysis of the internal environment, product plan, marketing plan, and financial plan have structured a product robust and commercially viable for hospitals of this size, since there is a lack of information systems geared to this audience.

This system would consist of 10 integrated modules with one another, which would provide information to employees including via remote connection and web platform. The modules would be the following: hospital management, hospital support, hospital billing, particularly comptroller and covenants, billing the SUS, clinical administrative management, clinical management, diagnostic and therapeutic service, supplies, and technological support systems.

The full implementation of this system benefits public management, as it allows the crossing of various natures information coming from different locations, producing valuable information such as epidemiological distribution, occupancy rate of beds and medical area professionals distribution which allows public health managers more accurate analyses and the development of more efficient strategies.

The concentration of health units able to care of medium and high complexity in the two largest cities in the State of Rio Grande do Norte, Natal, and Mossoró, causes a swelling in the hospitals of these cities, being one of the reasons a lot of patients coming from other cities. Within this context the HMGF provides service to a region with a population of more than 400,000 people, since apart from the municipalities of its regional health, people coming from other areas, including the State of Paraiba, seek the HMGF for consultations, surgery, and hospitalization. In order to provide the expansion and growth of these services, two projects in different lines were prepared, but equally important in the population. The first was creating a diagnostic sector and orthopedic care of medium complexity, which involves the restructuring and expansion of current facilities and hiring of specialized professionals. This project was developed with the idea of offering the most complete service area population, decreasing the need for these to go along long distances in search of care. This directly impacts on the effectiveness of patient care and public health system efficiency, since from a balanced distribution of the demands there will be a reduction of quotas in the major cities, from the queues of waiting for consultations and surgical procedures.

The realization of this project had the following objectives: prevention and treatment of diseases of the brain and cervical order, to analyze rich of fractures related to bone changes, perform cardiology accompaniments, develop gastrointestinal analyses, perform mammography examinations for prevention and treatment, blood analysis, and to perform diagnostic imaging, surgical interventions and evaluation of cardiology after-treatment. For both were provided for a series of civil works and procurement of miscellaneous 
equipment, as well as hiring and training of professionals to work in the area.

Another project developed seeking the extension of the range of services was the deployment of a wing of the maternal and child health care capable of giving to the population of the region medical services such as examinations, surgeries, and treatments geared to the mother and the child. Attention to this area has a high relevance for the region, as the maternal and child health indicators such as infant mortality rate, neonatal mortality, perinatal mortality, maternal mortality rates are among the highest of the Brazilian States influencing directly on regional development.

From the perspective of fundraising, the fruits of the partnership are based on three HMGF/UFRN projects-being a product development and expansion and restructuring two-hospital managers have a greater chance of success when pleading appeal to funding agencies, development banks and government agencies. Bypassing the line of action of projects can still be cited eight scientific articles presented in Congress and another six published in journals, as well as two monographs, all of these indicating the success of the partnership.

\section{Conclusions}

The improvement in the health of the Brazilian population did not follow the advancement of economic indexes of the nation in recent years. In a country with very high tax rates, which is invested in public health is not yet the required value, what is proved by those who need the services of SUS. Designed to be a universal system and ensure quality care in health care to citizens who so request, the reality of the numbers of the SUS is completely different from objectified in your project. There are doctors, beds, basic physical structure, materials, and necessary medical equipment to health problems of the population.

Seeing this, the university-business partnership featured in this survey pointed to a change in the reality experienced by HMGF, reality fairly close to that experienced by SUS because it is directly dependent on this, while it encourages those who are inside the university a broad vision of the current situation of the society in which they are inserted. While the university hospital board delivers technical knowledge regarding management strategies, also cares about the other needs of the organization, pointing out that the major difficulties faced by the hospital fall in the absence of sufficient financial resources to cover what it is necessary to raise the institution to a better level of service to their target population.

Equally difficult is the search for sources of funds and the return of those who are willing to invest in this issue, which is worrisome given the relevance of the theme in the health problems experienced by society. Thus, in addition to the delivery of a different vision as regards the way in which it sees the hospital day after day, the projects for financial-fundraising and other scientific papers are presented as the results of the university-company partnership highlighted in the case of the search.

In this way, the partnership can prove HMGF/UFRN effectiveness of benefits of mutualism between the university and the company, to the extent that the initial goal of the extension project which led to the drafting of the article was reached when the students were able to apply the knowledge acquired in the classroom within the perspective of the problems faced by the hospital, while the hospital has benefited from that knowledge to apply to methods, human resource processes, and available for carrying out the procedures of daily life at the hospital.

Similarly, the overall objective of the article was fulfilled and its research problematic was solved, since it is presented as the university-business partnership is important in the search for effectively promoting solutions 
to today's shortages experienced by the public health sector, and even what stage the resolutive power of this strategic partnership is able to bring clear benefits to both institutions.

The search does not allow methodological option by itself that the peculiarities provided in case the job object can be extended to other Brazilian States. We then question about the possibility that extension of reality presented to other localities of Brazil, thus encouraging other researchers to further develop this theme, in seeking to promote new solutions-either in university-business partnership, or by other methods-for problems faced by hospitals, with a view on the current situation of significant improvement of public health in Brazil.

\section{References}

Adulis, D. (2001). The labor market and management in the third sector (O mercado de trabalho e a gestão no Terceiro Setor). São Paulo: Rede de Informações sobre o Terceiro Setor (RITS).

Adulis, D. (2002a). How to plan an evaluation of a social project? (Como planejar a avaliação de um projeto social?). São Paulo: Rede de Informações sobre o Terceiro Setor (RITS).

Adulis, D. (2002b). The use of the logical framework in the management and evaluation of projects (O uso do marco lógico na gestão e avaliação de projetos). São Paulo: Rede de Informações sobre o Terceiro Setor (RITS).

Brasil Lei $n^{\circ}$ 1,920. (1953). Creates the Ministry of Health and other measure (Cria o Ministério da Saúde e dá outras providências). Diário Oficial da República Federativa do Brasil, Brasília.

Cruz, M. C. T. (2012). Fundraising: A means to achieve its mission (Captação de recursos: um meio para se atingir sua missão). Retrieved

from

http://www.portaldomeioambiente.org.br/editorias-editorias/terceiro-setor/onde-obter-recursos/30-captacao-de-recursos-ummeio-para-se-atingir-sua-missao

Falconer, A. P. (1999). The promise of the third sector: A study on the construction of the role of organizations (A promessa do Terceiro Setor: um estudo sobre a construção do papel das organizações). Chile: International Society for Third Sector Research-ISTR.

Lazzarini, S. G. (1995). Case study: Applicability and limitations of the method for research purposes (Estudo de Caso: aplicabilidade e limitações do método para fins de pesquisa). São Paulo: Economia \& Empresa.

Ministério da Saúde. (2012). Ministry evaluates the quality of health services (Ministério avalia qualidade dos serviços de saúde). Retrieved from http://portalsaude.saude.gov.br/portalsaude/noticia/4390/162/ministerio-avalia-e-monitora-acesso-e-qualidade-dos-servicos-d e-saude.html

Ministério da Saúde. (2012). National network of integrated healthcare worker (Rede Nacional de Atenção Integral à Saúde do Trabalhador). Retrieved from http://portal.saude.gov.br/portal/saude/visualizar_texto.cfm?idtxt=25085\&janela

Niyama, J. K., \& Silva, C. A. T. (2008). Accounting theory (Teoria da Contabilidade). São Paulo: Atlas.

Olak, P. A., \& Nascimento, D. T. (2009). Accounting for nonprofit organizations (Contabilidade para Entidades Sem Fins Lucrativos). São Paulo: Atlas.

Olak, P. A., Slomski, V., \& Alves, C. V. O. (2008). Academic journals of accounting research in Brazil, within the third sector organizations (As publicações acadêmicas da pesquisa contábil no Brasil, no âmbito das organizações do Terceiro Setor). Revista de Educação e Pesquisa em Contabilidade, 2(1), 24-46.

Pereira, C. (2006). Sustainability and fundraising in higher education in Brazil (Sustentabilidade e captação de recursos na educação superior no Brasil). São Paulo: Saraiva.

Sartori, R., Franco, J., \& Pereira, M. F. (2003). Funding for the third sector: A study in the city of Maringá-PR (Captação de Recursos para o Terceiro Setor: um estudo na cidade de Maringá-PR). Rio de Janeiro: EnANPAD.

Silva, C. E., Menezes, E. R., Barbosa, M. A. S., \& Felizola, M. P. M. (2011). Historical evolution and management of the environmental institute arvore in the period 2003-2009 (Evolução da histórica e de gestão da ONG Instituto Socioambiental Árvore no período 2003-2009). Revista Brasileira de Administração Científica, 2, 53-67.

Szazi, E. (2005). Third sector: Controversial issues (Terceiro Setor: temas polêmicos). São Paulo: Peirópolis.

Tachizawa, T. (2007). Nongovernmental organizations and the third sector: Creation of NGOs and action strategies (Organizações não governamentais e Terceiro Setor: criação de ONGs e estratégias de atuação) (3rd ed.). São Paulo: Atlas. 
Valarelli, L. L. (1999). An expanded notion of fundraising (Uma noção ampliada de captação de recursos). Rio de Janeiro: Rede de Informações do Terceiro Setor (RITS).

Villas Bôas Neto, A., Stefani, M., \& Pezzi Junior, S. (2003). Marketing management for third sector organizations: Public, private (Gestão de marketing para organizações do Terceiro Setor: público, privado). Londrina: Midiograf.

Yin, R. K. (2001). Case-planning and methods (Estudo de caso-planejamento e métodos) (2rd ed.). Porto Alegre: Bookman.

Yin, R. K. (2005). Case-planning and methods (Estudo de caso: planejamento e métodos) (3rd ed.). Porto Alegre: Bookman. 